\title{
The Doha Development Agenda and the General Agreement on Trade in Services Negotiation and Regulatory Reform in Korea
}

\author{
Keuk-Je Sung*
}

\begin{abstract}
Economists argue that trade liberalization is good for every country involved in the process since, according to Ricardian theory, free trade would allow more trade, which, in turn, offers wider choices for consumers and allows the most efficient producers to concentrate on their specialty areas. This observation raises the issue as to whether the general public believes in such a proposition. If the answer to the question is not in the affirmative, then there must be other reasons why developing country members participate in trade negotiation. An attempt is made to resolve this issue from a new standpoint - the regulatory reform perspective with particularly reference to Korea. Even if this new perspective is satisfactory, the issue remains as to whether the general public can be persuaded by its intrinsic argument. However, a new and different answer definitely adds to the reasons why developing country members should participate in the services negotiation associated with The Doha Development Agenda and the General Agreement on Trade in Services Negotiation.
\end{abstract}

Keywords: Doha Development Agenda General Agreement on Trade in Services, Korea, Regulatory Reform

\section{INTRODUCTION}

Members of the World Trade Organization (WTO) have agreed to a new round of multilateral negotiation starting from year 2002 until the end of 2004. However, the deadline has been extended to almost a year already until the next Ministerial Conference in Hong Kong, China in 2005, and a general view is that the negotiation may be even extended until the end of 2006. This round of negotiation was named the Doha Development Agenda (DDA), not like the Doha Round as it used to be. Such a change in name was a reflection that more attention has to be paid to the needs of the developing country members compared to the previous rounds of negotiation. DDA contains many negotiation agenda, if not as ambitious as that of the Uruguay Round (UR). The major

\footnotetext{
- Professor, Graduate School of Pan-Pacific International Studies, Kyung Hee University, 1, Sochen-ri, Giheung-eup, Yongin-si, Gyeonggi-do 449-701, Korea, E-mail:kjsung@khu.ac.kr
} 
items on the agenda list include agriculture, services, tariffs on manufactured goods, and rules.

Generally, developing country members do not show much interest in the DDA, mainly because the agenda is for opening an expanded market. If the market opening is for the reduction of tariffs on manufactured goods or agricultural products, then some, if not all, developing countries may benefit from further liberalization. However, when the topic is for the liberalization of services, then the benefits to the developing countries would be very limited. Of course, if developed countries allow more service providers from developing countries, they may develop an interest in the services negotiation. Apart from this possibility, it is widely believed that developing country members do not have competitiveness in services, and, accordingly they could be quite reluctant to participate in the services negotiation.

Generally, economists argue that trade liberalization is good for all the countries involved, since free trade would allow more trade, which offer wider choices for consumers and allow the most efficient producers to concentrate on their specialty areas. Such a view rests on the time-honored economic principle of Comparative Advantage Theory developed by David Richardo. Can developing country members be persuaded by such a theory? Does the general public believe in such a theory? If the answers to these questions are not affirmative, then there must be some other reasons why developing country members should participate in the negotiation. This paper tries to answer this question from a different perspective, namely from that of regulatory reform. It is true that even if this new perspective is satisfactory, the question whether the general public can be persuaded by it is quite another matter. However, if we can have a new and different answer, such an answer can definitely add to the reasons why developing country members should participate in the services negotiation.

\section{SERVICES NEGOTIATION IN THE DOHA DEVELOPMENT AGENDA}

The UR agreement, though not usually known, incorporated certain provisions so that a new round of negotiation can automatically start in some areas. There are some 30 separate negotiation agendas, but the major ones are on agriculture and services. The starting date for negotiation on agriculture and services was January 2000. Mindful of these 'built-in agenda', the first and second Ministerial Conferences instructed negotiators to prepare and discuss other negotiation agendas, since there would not be many members who would be willing to participate negotiation if the agendas are confined to agriculture and services. In multilateral negotiations, a long list of agenda is quite normal, since such a long list allows participants to trade-off benefits and costs across agenda, and it is also easier for them to persuade at least politically the general public to accept the negotiated outcome.

However, the list became too long and still most developing country members did not want a new round of negotiation, contending that their burden of implementing 
existing UR agreements is too heavy, and that the developed countries did not show meaningful implementation results. This was the major reason why the Third WTO Ministerial Conference held in Seattle turned into a failure, contrary to the general perception that the violent demonstration by NGOs was the major reason. This reluctance also put the Fifth WTO Ministerial Conference held in Cancun onto a failure track.

Although the Third WTO Ministerial Conference in Seattle has failed, negotiations on agriculture and services had to start, regardless of the outcome of the conference as they were mandated by the UR agreements. As can be expected, the pace of negotiation was rather slow. Participants, however, were able to discuss many items necessary for the upcoming market opening negotiations in services. They discussed rule makings in the services area, including those on safeguards, subsidies and government procurement; further elaboration on domestic regulation, classification, and even review on Most Favored Nation (MFN) tariff exemption measures. According to the articles in the General Agreement on Trade in Services (GATS), if a round of negotiation is to start, guidelines and procedures have to be adopted. Thus, during the year 2000 and 2001, members continued discussions following this mandate, and in March 2001, they produced an agreement on the Negotiation Guidelines and Procedures (S/L/93). Even if the outcome was successful, there was one critical element in that agreement - the deadline of the negotiation. The decision on the deadline had to wait for the conclusion of the Qatar Ministerial Conference.

DDA was officially announced in November 2001 in Doha, Qatar, and it contains many negotiation agendas. Negotiation agenda in services as stipulated in the Doha Development Agenda (DDA) is no different from the one in the Negotiation Guidelines and Procedures. However, the timetable for negotiation was included and the major key dates are: initial requests for market access by 30 June 2002; initial offers of market access by 31 March, 2003; and stocktaking at the Fifth WTO Ministerial Conference, 2003, (in Cancun, Mexico), and the conclusion of negotiation by December 2004. All negotiation outcomes, including those on services, are to follow a single undertaking procedure. As of the time of writing, it was already agreed to extend the negotiation by the Sixth WTO Ministerial Conference to be held in Hong Kong during 2005, and there is some speculation that the negotiation may be extended to 2006 , reflecting the power exerted over proceedings by the negotiation authority of the US administration.

At the onset of the DDA services negotiation in 2002, it was agreed that the negotiation should take place in Special Sessions of the Council for Trade in Services (CTS), which is no different from the regular CTS in terms of membership. Both sessions are usually held back-to-back, and a simple announcement would convert regular CTS into a special CTS. This was the practice of services negotiation from 2001.

\section{Negotiation agenda included in S/L/93 are;}

There shall be no a priori exclusion of any service sector or mode of supply. Special attention shall be given to sectors and modes of supply of export interest to 
developing countries.

MFN Exemptions shall be subject to negotiation according to paragraph 6 of the Annex on Article II (MFN) Exemptions. In such negotiations, appropriate flexibility shall be accorded to individual developing country Members.

Negotiations on safeguards under Article X shall be completed by 15 March 2002 according to the Decision adopted by the Council for Trade in Services on 1 December 2000. Members shall aim to complete negotiations under Articles VI:4, $X I I I$ and XV prior to the conclusion of negotiations on specific commitments.

This list basically means that all service sectors will be subject to negotiation, including those on maritime transport services (for which negotiation was suspended in 1996) and air transport services (air traffic rights and directly-related services are excluded from the services sector under the GATS). Also, MFN exemption measures are subject to negotiation, with the aim of reducing or eliminating them. These measures refer to the market access negotiations; there are also negotiations on the rules. They are on domestic regulations, emergency safeguard measures, and government procurement. GATS is still a young agreement, and there are many provisions to be elaborated. During the UR, those provisions were left for further negotiation in the future.

General assessment of the progress in the DDA negotiation is that it was slow and unsatisfactory. But in the case of services, the progress is not necessarily as bad as those in the other agendas. This was also true during the UR negotiation. There are many reasons, but one of them is that there are too many technical, not political, items to discuss in services trade, since the services agreement (GATS) is a new agreement, and it encompasses as many as 155 sectors, widely different and quite comprehensive.

Among 149 WTO members, only 55 members have submitted initial offers on the table by the end of last year and not much progress was made during 2004. But these services people remain in discussion, and when they meet, even though slow, they do make progress. Korea ranks around 12 th in the world in its economic size and trading volume. However, its liberalization level in services did not match its rank during the Uruguay Round. According to one unpublished informal paper, Korea's level of liberalization was the 29 th among the WTO members. Korea is, however, actively participating in the DDA services negotiation. It has submitted request lists to 36 members, and received requests from 25 members. It has held over 60 bilateral negotiations until last year with 32 members.

Korea's new initial offer added many new sectors, including legal services, real estate services, lease services, courier services and education services, although limited, entertainment services, rail and pipeline transport services. More significant is the abolition of restrictions in many important sectors, and horizontal measures. They are mostly in professional services, construction services, distribution services, environmental services, telecommunication services, and financial services. Last, but not the least, 
important feature of the Korean offer is the elimination of all, even though there was only one, MFN inconsistent measure. Of course, there still remain some restrictions in the film industry, medical and education services.

\section{APPROACHES TO LIBERALIZATION UNDER GENERAL AGREEMENT ON TRADE IN SERVICES}

Liberalization of trade means the reduction or elimination of trade barriers. In the case of the GATT which oversees trade in physical, tangible goods, trade basically means crossborder trade, and the barriers are mostly found at the border; tariffs, quotas, standards conformity testing, customs inspection, customs valuation, and so on. However, in the case of the GATS, it includes a mode where services are provided in a country after a company is established. The foreign service supplier is just like the ordinary local service supplier. It is called "commercial presence" (mode 3)'. Thus, if we pursue liberalization under the GATS, we have to consider the removal of all domestic regulations that affect the provision of services. This is a formidable task, and for many members, this would be viewed as infringement over their sovereignty.

GATS negotiators recognized the subtleties and difficulties, and came to devise a mechanism how liberalization can be pursued under this circumstance. First some terminologies need to be defined. The GATS is to be applied to "measures" by a Member, whether in the form of a law, regulation, rule, procedure, decision, administrative action, or any other form. Among these measures, some may be trade restrictive while others are not; not all measures are to be streamlined or removed, and such removal would be impossible in practice. Negotiators identified and certain rather trade-restrictive measures which need to be negotiated for removal, and let all the remaining measures to be streamlined according to certain principles.

Those measures that need to be removed (of course, through negotiation) are called "restrictions" or "limitations" and there are two types of limitations (hereafter it is called "limitations"). The first one is limitation on market access, and the other is on national treatment. Limitations on national treatment are rather straightforward; they are discriminations against foreign services or service suppliers. In GATS, Article 18 stipulates;

In the sectors inscribed in its Schedule, and subject to any conditions and qualifications set out therein, each Member shall accord to services and service suppliers of any other Member, in respect of all measures affecting the supply of

\footnotetext{
1 There are four such modes. Mode 1 is called cross-border supply, mode 2 consumption abroad, mode 3 commercial presence, and mode 4 movement of natural persons. Mode 2 refers to the cases where consumers move abroad to receive services, and mode 4 refers to the cases where foreign individuals move into other countries and provide services. What is important in these modes is that all four modes are defined as "trade in services", not the provision of services in the ordinary sense of the words.
} 
services, treatment no less favourable than that it accords to its own like services and service suppliers.

Conditions and qualifications set out in the National Schedules of Specific Commitment are the limitations in the meaning discussed here. ${ }^{2}$ Of course, the limitations include de jure and de facto discriminations. But discrimination here does not include any inherent competitive disadvantages that result from the foreign character of the relevant services or service suppliers.

The second type of limitation is on the market access. Limitations in this type, in contrast to the national treatment, are exhaustively listed in the Article 16 of the GATS. That is, a measure will be a market access limitation if it falls into one of the categories listed in the Article 16, and if not, it is not a market access limitation. There are six categories and they are;

(a) limitations on the number of service suppliers whether in the form of numerical quotas, monopolies, exclusive service suppliers or the requirements of an economic needs test;

(b) limitations on the total value of service transactions or assets in the form of numerical quotas or the requirement of an economic needs test;

(c) limitations on the total number of service operations or on the total quantity of service output expressed in terms of designated numerical units in the form of quotas or the requirement of an economic needs test;

(d) limitations on the total number of natural persons that may be employed in a particular service sector or that a service supplier may employ and who are necessary for, and directly related to, the supply of a specific service in the form of numerical quotas or the requirement of an economic needs test;

(e) measures which restrict or require specific types of legal entity or joint venture through which a service supplier may supply a service; and

(f) limitations on the participation of foreign capital in terms of maximum percentage limit on foreign shareholding or the total value of individual or aggregate foreign investment.

On a close examination, it is not difficult to note that (a) relates to the number of suppliers. (b), (c) and (d) are the limitations on the operation of the business in volume and quantitative forms, and the number of employees respectively. (e) is a limitation on

\footnotetext{
2 Limitations are to be inscribed in a document, and this document describes the market opening commitment of a member. It is called National Schedules of Specific Commitments.
} 
the form of the establishment and lastly (f) is foreign equity limitation. One should note that all these limitations are on the maximum, not on the minimum quantitative restrictions. If there are limitations on the minimum, they are usually considered as measures to ensure the quality of the service suppliers. Of course, if the minimum is too burdensome, that measure can be challenged under the Article 6 Domestic Regulation, which will be explained below. Another point to note is that all except (e) can be expressed in terms of numbers. In this sense, market access limitations are basically numerical limitations or in the terminology of the GATT, quantitative restrictions. This logic also applies to 'economic needs test' in (a) through (d). They are usually in the form of formulas. Many members, however, interpreted this 'economic needs test' as meaning 'discretionary criteria' by the licensing authority, but what negotiators had in mind was a limitation which can be expressed as a ratio such as one supplier per 1,000 residents.

Now, GATS approach to liberalization proceeds as follows. First, a member should determine which sector is to open to foreign competition. Of course, the choice of sectors has to be negotiated with trading partners. Once a sector has been chosen, then the member should review all government measures pertaining to this sector. Then, the member should identify any discriminative measures against foreign services or service suppliers. After such identification, it has to check whether there are measures, which fall into one of the six categories in the Article 16. These discriminatory measures and six types of measures constitute the limitations to national treatment and market access. Depending upon the outcome of negotiations, a member may maintain all or part of limitations. These limitations are inscribed in the National Schedule of Specific Commitments.

\section{DOMESTIC REGULATION AND REGULATORY REFORM}

There are numerous measures in the services sector in a particular country but only a small set of measures will impose limitations on national treatment or market access. In fact, most of the measures are on the qualification or licensing procedures. Most measures are not limitations to national treatment or market access, and these measures need not be negotiated to remain as government measures. Government may maintain any such measures, and no trading partners are entitled to request to remove such measures. However, Article 6 stipulates that such remaining measures should be administered in a reasonable, objective and impartial manner. Moreover, all qualification requirements and procedures, technical standards and licensing requirements do not constitute unnecessary barriers to trade in services, and such requirements are, inter alia:

(a) based on objective and transparent criteria, such as competence and the ability to supply the service;

(b) not more burdensome than necessary to ensure the quality of the service;

(c) in the case of licensing procedures, not in themselves a restriction on the supply of 
the service.

However, these requirements do not apply to all government measures, but only those measures in the sectors where specific commitments are made. Let us suppose, for sake of argument, that there is a measure, which a member wants to maintain. If that measure is a limitation to national treatment or market access, then through negotiation, a member may maintain the measure. If the negotiation was unsuccessful, then such a measure cannot be maintained. But when the measure is not a limitation, then a member may maintain the measure, but the measure should be administered according to the Article 6. Of course, if the sector is not on the National Schedule, then the Article 6 basically does not apply, and the member does not have any obligations. ${ }^{3}$.If there are specific commitments in the sector, then trading partners may request the removal of the measure if they believe that the measure was not administered in accordance with the Article 6.

At present, the Article 6 has only abstract principles, and it is not clear whether these principles would be operational in actual implementation. The GATS mandates members that they start negotiation to develop detailed principles. This Article 6 seems most controversial to the eyes of the opponents to the GATS. Indeed, this article lies at the heart of the assertion that "additional constraints on "domestic regulation" are among the most serious new threats to democracy posed by this round' as remarked by some NGOs against services liberalization and also globalization. This kind of allegation is not groundless, but, in reality, no government may deny that their measures should satisfy the criteria in the Article 6 . In fact, these are the criteria every government in the world pursues during their regulatory reform.

The way liberalization is pursued under the GATS has important relevance to the regulatory reform. In the introduction, we raised the question why should WTO members, especially developing country members participate in the negotiation? The initial rationale was based on comparative advantage. Generally, it is argued in the WTO that developing countries have comparative advantages in both the tourism sector, and human services sector. Regarding the tourism sector, it is a global trend that all the countries try to liberalize the sector to attract foreign capital and foreign tourists. Also it is not the restrictions imposed by developed countries restrictions that inhibit trade in this sector, but the restrictions imposed in the developing countries themselves. Some members alleged that unfair practices by transportation carriers, travel agencies or multinational hotel chains of developed countries prevent developing countries benefiting from tourism. Such claims have more to do with competition safeguards than either market access or national treatment limitations. Regarding movement of natural persons, developing countries strongly demand that developed countries should significantly expand their current offer in this mode. It is true that developing country members would benefit if the

${ }^{3}$ Some obligations such as transparency still apply. 
commitments are expanded, but movement of people also entails many social and political difficulties in many developed countries. It necessarily invites immigration aspects. There would be a limit to the pursuit of this effort.

The next argument for participation could be that liberalization increases efficiency in the economy as a whole. Some of the services sectors are important in themselves, as they are huge, but they are also important in supporting the manufacturing sector. They are mostly in the infrastructure services, such as distribution, telecommunication, transportation, construction and financial services. Without proper development of these sectors, manufacturing and even agricultural sectors cannot sustain growth. This is a very important economic argument, and Korea has emphasized this argument during the services negotiation. But the response was not warm enough, since the effect of such increased efficiency would be felt only in the long term.

In addition to this argument, this paper puts forward that the liberalization approach under GATS squarely fits the regulatory reform efforts of a country. There is not a generally agreed definition of regulatory reform, but we can turn the question around. That is, if a regulatory system does not impose restrictions including numerical quotas, and if the rules of the game are reasonable, objective and impartial, then such a regulatory system successfully passes the test of regulatory reform. If we accept this criterion, then that is exactly what GATS is pursuing. You set up rules, there are no numerical restrictions, and leave the market alone. But if the rules are violated, then punishment is meted out. The message is that you do not prejudge what is the desirable outcome beforehand and set up quotas based on pre-judgement. Moreover, all these approaches are committed not only to you, but to the outside (foreign) players, and it is practically impossible to reverse this approach.

Under this approach, three points require further elaboration. Firstly, there is the task of the identifying and eliminating numerical restrictions. Regulatory reform is based on the market economy principle, and the principle, in turn, has to be based on free competition. The most direct and distorting barrier to free competition is the numerical quota. Repeatedly, we have seen that the market is very distorted when there are entry barriers. Indeed, numerical quotas directly give rise to such entry barriers. As noted previously, the GATS approach puts the highest priority on the identification and elimination of numerical quotas. This is one of the reasons why GATS is based on the market economy principle and serves the purpose of regulatory reform. Next, follows a discussion of the principle of how government measures should be administered. Although the GATS domestic regulation has set forth only the general principle that all measures be administered in objective, reasonable and impartial manner, this would create significant constraint to the administration of government measures. Also, because it is general, it is hard for any government to deny that they would not follow this principle. On the other hand, if the principle is too general, one may think that it may not have practical impact. However, if there arises a dispute, and a panel examines the case, then it is not difficult to expect that the panel would scrutinize the case and all related matters will be publicly known. This can create another pressure on governments. Last is the 
nature of commitments in the WTO. Once commitment is made, it is virtually impossible to retreat from it. It is said in the WTO circles that the Organization is the only place to play a 'permanently and legally binding game'. Many, if not all, reforms fail, because they were reversed when the resistance from the interest groups is strong. Basically, you are tying your hands by making commitments in the WTO. All of these aspects show that GATS negotiation process can be a handy instrument in regulatory reform of the services sector.

Some people see the WTO as an intrusion into national sovereignty. However, if we want regulatory reform, and if we do not want interest groups to exercise their rent seeking power, this is what should be done, even without GATS. With the GATS, your intention and determination to reform is reinforced. You bound yourself internationally, and permanently.

\section{CONCLUDING REMARKS}

This paper attempted to develop an argument, mainly from the viewpoint of a developing country, about why it should participate in the services negotiation. The usual rationale is the increased benefit to be derived from comparative advantage, and increased efficiency of an economy, but those reasons would not be enough to persuade the negotiators and the general public. In this paper, the GATS liberalization approach has been analyzed from the perspective of regulatory reform, and it was contended that GATS liberalization can be a very appropriate instrument for regulatory reform from three aspects: market-based reform, regulatory principle, and irreversible commitment. It is true that this argument may be persuasive to negotiators and regulators, but not to the general pubic. Even so, it gives a good rationale to why the general public should actively participate in the services negotiation.

The aspect of irreversible commitment is particularly important to developing countries. It is quite common that powerful interest groups exist in developing countries, and often times they exercise political clout to reverse certain policies to their benefit. In developing countries, there is virtually no one who can resist such pressure. But if the commitment is made in a multilateral forum, such pressure can easily be denied. In fact, there were several occasions in the WTO, although not recorded, where developing countries voluntarily made deeper commitment beyond their ability to resist such domestic pressure.

In liberalizing trading regimes for developing countries, several additional considerations are also important. First is the MFN principle. That is, if liberalization is pursued, then the opportunity should be given not just to a limited number of foreign countries, but also to all foreign countries. If limited opportunities are given, some foreign firms will quickly convert into becoming powerful local firms. Thus, the benefit from liberalization will not be realized. Next is the ineffectiveness of gradual liberalization. Often, gradual steps are taken for liberalization to minimize the cost and smooth the 
transition. Such a gradual approach does have merits, but if the steps taken are far apart, then protectionist pressure is revived, and liberalization will cease. Finally, firms will always find ways to realize profitable opportunities. That is, if proper incentives are not given, any regulation may be circumvented, even if it is illegal. If the regulation goes against market incentives, it would not work.

\section{REFERENCES}

Choi, Nag-gyun and Kim, June-Dong, 2003, Mid-term Review of DDA, December, Korea Institute for International Economic Policy, Seoul (in Korean).

Ministry of Foreign Affairs and Trade, 2004, Stock-taking of DDA Negotiation, 2004-5, August 4 (in Korean).

Republic of Korea, 2003, Initial Offer in Services under GATS, June.

Sung, Keuk-Je, 2000, Negotiation Strategy for the Abolition of MFN Exemption in the WTO/GATS), Report to the Korean Ministry of Foreign Affairs and Trade, September, 2000 (in Korean).

Sung, Keuk-Je, 2002, Introduction to GATS Part I and II, KDI On-line Education Session, November.

WTO, 2004, GATS Telecommunication Regulatory Principles, Trade in Services

Division, September.

WTO, 2001, Negotiation Guidelines and Procedures, S/L/93, March. 